\title{
Indústria Criativa made in Brazil: Rock in Rio
}

\author{
Creative Industry made in Brazil: Rock in Rio
}

\section{Industria creative hecha em Brasil: Rock in Rio}

\author{
Flávio Lins \\ Universidade Federal de Juiz de Fora - MG - Brasil \\ ORCID: https://orcid.org/0000-0002-1869-2194 \\ Endereço currículo Plataforma Lattes: http://lattes.cnpq.br/6027133580735662 \\ E-mail: flavio.lins@ufjf.edu.br
}

\author{
Maria Helena Carmo dos Santos \\ Faculdades Integradas Hélio Alonso (FACHA) e Faculdade de Comunicação Social (UERJ) \\ ORCID: https://orcid.org/0000-0002-3562-7677 \\ Endereço currículo Plataforma Lattes: http://lattes.cnpq.br/906992317362282 \\ E-mail: mhcarmo@yahoo.com.br
}

Resumo: A indústria criativa como força propulsora da economia de uma cidade é o mote deste artigo que propõe analisar o evento Rock in Rio como um exemplo modular da economia criativa no Brasil. Para isso, faz-se um breve panorama sobre o conceito de economia criativa no país, a história do festival e como ele se encaixa em uma economia ancorada em bens e serviços que mescla dois segmentos criativos: cultura e consumo.

Palavras-Chave: Economia Criativa. Cultura. Rock in Rio.

\begin{abstract}
The creative industry as a driving force of a city's economy is the theme of this article, which suggests to analyze the Rock in Rio event as an example of the creative economy in Brazil. Therefore, a brief overview of the Brazilian concept of creative economy is made, the history of this festival and how it fits into an economy anchored in goods and services that joins two creative segments: culture and consumption.
\end{abstract}

Keywords: Creative Economy. Culture. Rock in Rio.

Resumen: La industria creativa como motor de la economía de una ciudad es el tema de este artículo, que propone analizar el evento Rock in Rio como un ejemplo modular de la economía creativa en Brasil. Por eso, se hace un breve recorrido por el concepto de economía creativa en el país, la historia del festival y cómo es parte de una economía anclada en bienes y servicios que mezcla dos segmentos creativos: cultura y consumo.

Palabras clave: Economía Creativa. Cultura. Rock in Rio. 


\section{Introdução}

Há algum tempo relaciona-se a Economia Criativa ao potencial de desenvolvimento econômico de cidades e países por meio de políticas públicas que incentivem ações criativas. Mais recentemente, como parte da Economia Criativa no espaço urbano, tem sido selecionadas 'cidades criativas', as quais geralmente se destacam pela gastronomia e produção audiovisual, por exemplo.

No estudo "Tempos de Cultura: O primeiro mapa global das indústrias culturais e criativas" (ERNST \& YOUNG, 2015), em 2013, essas indústrias geraram uma receita de R \$ 9.360 bilhões em todo o mundo - África e o Oriente Médio, Europa, Ásia-Pacífico, América do Norte e América Latina, totalizando 3\% do Produto Interno Bruto (PIB) e empregaram 29,5 milhões de pessoas. Em resumo, cerca de 1\% da população ativa no mundo trabalhavam em 11 setores naquele ano: televisão, artes visuais, jornais e revistas, publicidade, arquitetura, livros, artes performáticas, games, cinema, música e rádio.

Segundo o estudo, especificamente sobre a América Latina, outro dado apontado é que as indústrias culturais e criativas (ICC) da região geraram R $\$ 515$ bilhões em receitas (pelo câmbio atual), 6\% do mercado mundial das ICC, e 1,9 milhões de empregos (7\% do total de empregos das ICC). A América Latina e a região do Caribe possuem um rico patrimônio cultural e natural, com 131 sítios inscritos na Lista do Patrimônio Mundial e vários autores da América Latina já alcançaram reconhecimento mundial. Nesse mesmo documento, “a vida social nos países desta região é frequentemente moldada por festas tradicionais, incluindo o Carnaval do Rio de Janeiro, no Brasil, o Festival da Virgen de la Candelaria, na Bolívia, e o festival de Inti Raymi, em Cusco, Peru". Em relação ao segmento música, o "Rock in Rio" é citado como um dos maiores festivais de música do mundo, com origem no Rio de Janeiro e depois exportado para Lisboa, Madri e Las Vegas (ERNST \& YOUNG, 2015).

A partir desta breve discussão, é possível inferir que a Economia Criativa não é apenas uma classificação da nova economia, mas sim uma nova economia, um novo paradigma, na qual a informação transita em grande velocidade e a criatividade se torna um ativo intangível de grande valor agregado, que gera diferencial, inovação, visibilidade e principalmente valor financeiro. Nessa perspectiva, é que o estudo se propõe a analisar o Rock in Rio como um festival de música, um produto cultural de alto valor agregado a ser consumido local e internacionalmente. 


\section{A Economia Criativa}

Originalmente, o conceito "Economia Criativa", usado pela primeira vez por John Howkins, no livro "The Creative Economy - How people make money from ideas", de 2001, consiste em atividades nas quais a criatividade e o capital intelectual são a matéria-prima para a criação, produção e distribuição de bens e serviços (BLANCO, 2015). Para Andrea Matarazzo, autor do projeto "Distritos Criativos" em São Paulo, o termo envolve uma "cadeia produtiva baseada no conhecimento e capaz de produzir riqueza, gerar empregos e distribuir rendas", ou seja, gera um impacto social” (SÃO PAULO, 2015).

No entanto, o termo surge em 1983, em um relatório sobre tecnologia e criatividade para o crescimento econômico de um país, "publicado pela primeira ministra Margaret Thatcher, pela primeiríssima vez em que se reconheceu oficialmente a importância de áreas ligadas à tecnologia e à criatividade para o crescimento econômico do Reino Unido", afirma Renata Reps (apud CASTRO, 2014, p. 15), mestre em Indústrias Criativas pela Universidade Paris 8. Gisela Branco (2015) pontua ainda que, em 1994, o primeiro-ministro australiano Paul Keating lançou o "Creative Nation", primeiro documento sobre políticas públicas de um país com foco em cultura e arte.

Em reportagem para The Guardian, se encontra a afirmação de que "o amadurecimento da Economia Criativa em países como China, Coreia do Sul e Brasil começa a ameaçar a liderança histórica do Reino Unido em indústrias criativas, como música, moda e artes visuais" (THORPE, 2016). Isso significa que as nações começavam a observar a economia criativa como um setor relevante do sistema social e que possui impactos significativos e duradouros (PORTER, 1990). Ou seja, a Economia Criativa é um recorte feito por especialistas e governos para medir o impacto econômico e social de setores e indústrias, por meio da geração de conhecimentos, bens e serviços, em que a criatividade humana é a matéria-prima essencial na geração do valor simbólico e intangível, determinante no valor real do negócio e que ganha mais relevância no século XXI por conta da era pósindustrial, a exemplo dos setores de design, arquitetura, gastronomia, moda e artesanato. 
Segundo a United Nation Conference on Trade and Development (UNCTAD) ${ }^{1}$, as indústrias criativas, formadas por setores como publicidade, arquitetura, artes e artesanato, design, moda, cinema, vídeo, fotografia, música, artes performáticas, pesquisa e desenvolvimento, software, games e editoração eletrônica, englobam ciclos de criação, produção e distribuição de bens e serviços que usam a criatividade e o capital intelectual como insumos primários e representam importantes fontes de valor econômico e cultural que geram riqueza, impacto social e diversidade.

De acordo com o mais recente Mapeamento da Indústria Criativa no Brasil produzido pela FIRJAN SENAI (MAPEAMENTO, 2019), esse segmento gerou R\$ 171,5 bilhões em 2017, o que equivaleu a 2,61\% de toda a riqueza gerada em território nacional. Nesse mesmo estudo, foi mantida a divisão dos 13 segmentos criativos, por afinidade setorial, agrupados em quatro grandes Áreas Criativas: Consumo (Design, Arquitetura, Moda e Publicidade \& Marketing), Mídias (Editorial e Audiovisual), Cultura (Patrimônio e Artes, Música, Artes Cênicas e Expressões Culturais) e Tecnologia (P\&D, Biotecnologia e TIC). Outro dado apontado pelo Mapeamento destacou que, no biênio 2017-2019,

São Paulo e Rio de Janeiro seguiram como os estados mais representativos do mercado de trabalho criativo. Entre os paulistas, cerca de 328,7 mil vínculos estavam na Indústria Criativa, enquanto, entre os fluminenses, esse número ficou em 88,9 mil. Dessa forma, ambos os estados, juntos, responderam por exatamente $50 \%$ dos empregos criativos do país. Cabe destacar que, junto com São Paulo e Rio de Janeiro, Santa Catarina e Rio Grande do Sul compõem o rol de estados que mantiveram a participação de profissionais criativos acima da média nacional. (MAPEAMENTO, 2019, p. 5)

Segundo o Observatório do Itaú Cultural (FOLHA, 16/08/2021), no último trimestre de 2019 a economia criativa empregava 5,2 milhões de trabalhadores. No entanto, devido à pandemia Covid-19, as perdas econômicas em comparação a 2019 foram significativas, com o

PIB do setor de R \$ 129,9 bilhões em 2020 (redução de 31,8\% em relação a 2019) e $\mathrm{R} \$ 181,9$ bilhões em 2021 (próximo de retomar o patamar de 2019, porém ainda 4,5\% inferior). Dessa forma, a perda total do setor criativo brasileiro será de $\mathrm{R} \$ 69,2$ bilhões no biênio 2020-2021, o que representa perda de $18,2 \%$ na produção total do período (RELATÓRIO, 2020, p. 23).

1 A Conferência das Nações Unidas sobre Comércio e Desenvolvimento se autodefine como agente para gerar compreensão global sobre economia criativa desde 2004 em uma missão para promover o desenvolvimento por meio da criatividade. Disponível em: https://unctad.org/topic/trade-analysis/creative-economyprogramme. Acesso em:11 set. 2021. 


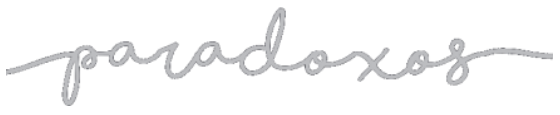

Especificamente no Rio de Janeiro, a Secretaria de Estado de Cultura e Economia Criativa do Rio de Janeiro (Sececrj) lançou em 2021 a chamada pública \#CarnavalNasRedesRJ a fim de "socorrer a indústria criativa do Carnaval e seus trabalhadores em todo estado" para premiação de atividades carnavalescas na internet, como escolha de sambas-enredos e apresentações musicais de blocos de carnaval. Outra iniciativa - o edital "Cultura Presente nas Redes" - tem o objetivo de fomentar propostas culturais (música, literatura, artes visuais, audiovisual, dança, teatro, circo, moda, museus, cultura alimentar e expressões culturais populares) executadas e transmitidas via internet por artistas em todo território fluminense, com recursos do Fundo Estadual de Cultura.

Em matéria sobre o impacto da Covid-19 no setor de eventos, a Associação Brasileira dos Promotores de Eventos (Abrape) sinaliza que mais de 350 mil eventos deixaram de ser realizados em 2020 (entre shows, festas, congressos, rodeios, eventos esportivos e sociais, teatro), o que fez com o setor deixasse de faturar ao menos R 90 bilhões (NEVES, 17/02/2021). Com o avanço da vacinação e da flexibilização das medidas restritivas, o setor parece ensaiar uma retomada gradual, e alguns grandes eventos já estão programados para 2022, como os festivais Lollapalloza e o Rock in Rio.

\section{Rock in Rio: Breve Panorama}

O festival de música Rock in Rio tornou-se uma marca que segue se consolidando internacionalmente, sendo realizado também na Europa e nos Estados Unidos, o que significa dizer que o empresário brasileiro Roberto Medina desenvolveu um festival cujo formato possui algum diferencial em relação aos eventos do gênero realizados nestes lugares, já que os artistas-âncora do festival são astros do show biz mundial, muitas vezes se repetindo, tal qual o repertório de canções. Além disso, os brinquedos da Cidade do Rock, como roda-gigante, montanha-russa e tirolesa, possibilitam um repertório de sensações. Ainda que o menu das lanchonetes não traga receitas novas, muitas vezes podem oferecer releituras temáticas de pratos já conhecidos. De maneira geral o espaço do festival é cada vez mais familiar e caprichado, como os banheiros, sendo o aumento do conforto responsável por muitos dos ajustes da arena do Rock in Rio a cada edição. Se enumeramos e observamos essas peças-chave na composição do espetáculo, somos desafiados a compreender o seu processo de consolidação, especialmente, em nível internacional. 


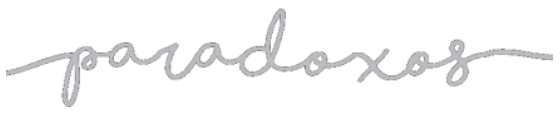

Na primeira edição (1985), o grande evento era visto com desconfiança pela imprensa norte-americana, que lamentava a invasão do rock no país pondo em risco a "exuberante música brasileira", sendo mais "um triunfo de técnicas modernas de marketing do que de paz e amor", ainda que ressaltassem o sucesso da iniciativa, inclusive para um possível florescimento do rock nacional (RIDING, 1985, p. 1-3). Em 2011, o músico Tony Bellotto escreveu um artigo sobre o Rock in Rio publicado no jornal Folha de São Paulo. No texto, o autor aborda diversos aspectos para tentar explicar o sucesso do festival, ressaltando a composição das palavras Rock + in + Rio, como "um dos mais belos poemas concretos do Brasil contemporâneo", que modificava a cara do Rio de Janeiro, se tornando peça-chave de uma reconfiguração do imaginário carioca. Ou, até, brasileiro.

Uma das razões que explicam o sucesso desse empreendimento - porque, afinal, o Rock in Rio é mais do que um festival, uma marca, um franchising, uma grife, uma pirâmide ou um parque de diversões - é justamente a capacidade que têm essas três palavras, Rock in Rio, de significar ao mesmo tempo tantas coisas diferentes, muitas vezes antagônicas, sempre reveladoras (BELLOTTO, 2011, Opinião, p.A3).

Sobre a efetividade comunicacional da poesia concreta, Campos, Pignatari e Campos (1975) salientam como o concretismo poético influenciou a linguagem da propaganda, bem como a formatação de jornais, revistas e livros. Para os autores,

A poesia concreta visa como nenhuma outra à comunicação. Não nos referimos, porém, à comunicação-signo, mas à comunicação de formas. A presentificação do objeto verbal, direta, sem biombos de subjetivismos encantatórias ou de efeito cordial. Não há cartão de visitas para o poema: há o poema (CAMPOS; PIGNATARI; CAMPOS, 1975, p.50).

Não se trata de reduzir o festival e os seus desdobramentos a um conjunto de palavras, mas reconhecê-las como "elemento primordial frente a qualquer conteúdo" (CAMPOS, PIGNATARI e CAMPOS 1975, p.50). Bellotto (2011), por sua vez, denota que já no surgimento da marca o empresário Roberto Medina desafia a lógica consolidada do show biz e propõe o Brasil como sede de um espetáculo de magnitude que despertaria o interesse de empresários, artistas, políticos, anunciantes e público. O Rock in Rio, dada à proporção de seu apelo midiático, alinhava-se ao imaginário da terra do samba, do carnaval e do futebol. Mas, em vez de desafiar e disputar com os outros elementos que formam o ideário da Cidade Maravilhosa como porta de entrada para o Brasil, o poema concreto de Medina esgota os 


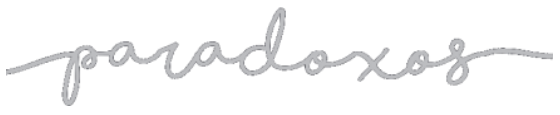

“aspectos sonoros, visuais e semânticos dos vocábulos" transformando-os em grande evento e consequentemente em negócio.

\footnotetext{
Ninguém àquela época relacionaria o substantivo rock à cidade do Rio de Janeiro. Se havia um lugar rock'n'roll no Brasil, era São Paulo. O Rio era a terra do Carnaval, do samba, da praia e das mulatas fornidas e inzoneiras (seja lá o que signifiquem esses arcaicos adjetivos). [...] o empresário Roberto Medina mudou a maneira como enxergávamos - e ouvíamos a nós mesmos. E, de quebra, forneceu uma resposta àquela esfinge pentelha que insistia em nos inquirir, impiedosa: "Mas afinal, quem são vocês?". "Nós somos isso", responderam as bandas brasileiras. Mesmo sem cenários e um arsenal de fotos de artifício, elas provaram que o rock brasileiro não quer abafar ninguém, só deseja mostrar que faz barulho também (e segue fazendo-o ininterruptamente desde então, não importa quantos padres cantores, políticos tipo Brizola e bichos escrotos em geral queriam calarlhe a boca) (BELLOTTO, 2011, Opinião, p. A3).
}

Bellotto evidencia o Rock in Rio como um festival que refaz e dá novo sentido à comunidade, seja ela carioca ou brasileira, ou até mesmo paulista, já que a partir daí evidencia-se a questão do local do rock, ainda que esta não seja a preocupação e nem a intenção de Medina, que quer consolidar o seu festival como plataforma de comunicação e negócios, não importando de onde vem o som, desde que atraia algumas dezenas de milhares de pessoas.

O Rock in Rio aumentava a temperatura da sociedade lançando no ar outras identidades possíveis, com "ampla possibilidade de desentendimento" (BAUMAN, 2005, p.19), já que as fronteiras identitárias são estabelecidas a partir da diferença, afinal: eu vou ou eu não vou? Eu sou do rock ou eu sou do samba? O rock é do Brasil? É do Rio ou de São Paulo? É coisa do diabo ou da igreja? É coisa de família?

As comunidades estéticas arranjadas por Medina, que podem se formar "em torno de um evento festivo recorrente" (BAUMAN, 2003, p.67), não só motivadas pelo grande evento do festival de música, mas pelo seu impacto de amplo espectro na vida social, compostas a partir do que Bauman (2003) chama de "identidades-estéticas" e a partir de "vínculos sem consequências", atribuem em sua aparente fragilidade e irrelevância, dado ao seu caráter de brevidade, força a estes acontecimentos.

Os túmulos dos ídolos precocemente desaparecidos constituirão no curso da vida dos espectadores verdadeiros marcos, que serão visitados e receberão flores nos aniversários; mas dependerá dos espectadores, que desde então mudaram, recuperar do esquecimento os desaparecidos por mais um instante passageiro (BAUMAN, 2003, p.66). 
Além do caráter passageiro e cíclico destes eventos, Bauman ainda explicita o papel de experienciar esses vínculos:

Como as atrações disponíveis nos parques temáticos, os laços das comunidades estéticas devem ser "experimentados", e experimentados no ato - não levados para casa e consumidos na experiência diária. São, podese dizer, "laços carnavalescos" e as comunidades que os emolduram são "comunidades carnavalescas" (BAUMAN, 2003, p. 68).

E é na disputa identitária ressaltada por Bauman (2005) e na sua capacidade de estabelecer vínculos, ainda que fugidios, que encontraremos pistas para compreender parte do estranhamento com o qual o Rock in Rio foi visto pela imprensa da América do Norte, berço dos festivais de rock. Tal qual escreveu Riding (1985, p.1), no New York Times, a primeira edição do festival, às vésperas do carnaval carioca, nascia aos olhos do mundo como um filho disforme de Carmem Miranda, Antônio Carlos Jobim e Roberto Carlos, artistas cuja música moldou a imagem do Brasil no exterior e conseguiu no país uma boa distância da música estrangeira.

Um público que resistiu ao assalto do rock na década de 1960 e 70 agora está se rendendo a ele. Televisão e estações de rádio, bem como as gravadoras têm trabalhado para criar um mercado jovem para o rock brasileiro e importados e, em seguida, definir sobre como satisfazê-lo. As estações de televisão têm programas diários de clipes de vídeo, enquanto o número de todas as estações de rádio dedicadas ao rock está crescendo (RIDING, 1985, p.1).

Somavam-se outros elementos pouco conhecidos à imagem do Brasil, como a existência de uma massa de roqueiros tupiniquins interessados por artistas e ritmos do gênero, bem como um vicejante grupo de artistas nacionais, desejosos de mostrar que a "exuberante" música brasileira não se se limitava aos artistas elencados por Riding (1985, p.1). Havia também o desejo de subir um degrau na escala de desenvolvimento, caracterizada por sediar um evento com estas proporções, capaz de chamar atenção do público e de empresas, colocando "as cidades no novo mapa do mundo" (SÁNCHEZ, 2010, p.29), dando forma a um tipo de liderança-empreendedora que tem a cultura "como parte decisiva do mundo dos negócios e o é como grande negócio" (ARANTES, 2012, p.48). Plantava-se ali a semente para que no futuro o Brasil pudesse sediar grandes eventos de outra ordem.

A Cidade Maravilhosa, mesmo tendo deixado de ser capital do país em 1960, seguia como capital cultural, dados aos "poderosos sistemas de representação que é detentora", 
como "sede das maiores empresas de comunicação" do país (LINS; BRANDÃO, 2012, p.63). Além disso, as imagens do Cristo Redentor, do Pão de Açúcar e de suas praias mais célebres, mesmo cariocas, bem como o samba e a bossa nova, consolidaram-se como ícones do Brasil ao longo do século XX, ainda que o samba tenha raízes mais amplas. Desta forma, tendo sido de fato durante algum tempo porta de entrada para o Brasil, além de capital da colônia, do império e da república, o Rio de Janeiro, equipado pela natureza com muitas belezas, via esses elementos energizados pelas mídias e pelas novas tecnologias que iam chegando através dos impressos, do rádio, do cinema e da televisão. Assim, acontecimentos e realizações que tomaram forma desde o descobrimento passaram a compor um mosaico que energizava o imaginário que se tinha sobre a cidade do Rio de Janeiro, dentro e fora do país, o que é explicitado por Azevedo:

A capitalidade é um fenômeno urbano que se caracteriza pela constituição de uma certa esfera simbólica originada de uma maior abertura às novas ideias por parte de uma determinada cidade, que confere a esta um maior cosmopolitismo relativo às suas congêneres e uma maior capacidade de operar sínteses a partir das diversas ideias que recepciona. Este conjunto simbólico que se desenvolve nas vicissitudes das experiências históricas vividas por esta urbe, identifica a cidade como espaço de consagração dos acontecimentos políticos e culturais de uma região ou país, tornando-a uma referência para as demais cidades e regiões que recebem a sua influência. Esta esfera simbólica evolui, sendo redimensionada ao sorver novas experiências, constituídas e constituidoras da tradição da urbe (AZEVEDO, 2002, p.45).

A trama simbólica citada por Azevedo (2002) irá se enlaçar às grandes festas que também marcam o imaginário carioca, Carnaval e Réveillon, além do ideário do paraíso natural, de um lugar onde não cabem preocupações, vocacionado para a cenografia e convívio entre artistas e público (PAIVA; SODRÉ, 2004). Neste contexto, em maio de 2014, o jornal inglês The Guardian publicou o resultado de uma pesquisa realizada pela empresa Saffron Brand Consultants que apontou o Rio de Janeiro, como a $7^{\mathrm{a}}$ marca de cidade mais poderosa do mundo, logo depois de Barcelona e na frente de cidades como Las Vegas, Madri, Washington e Veneza.

Assim, quando se reúne a palavra rock, embebida em juventude, energia, irreverência e rebeldia, com o adjetivo in, significando dentro, do Rio, por sua vez um nome encharcado de festa, cor, sensualidade e alegria, surge uma marca cujos desdobramentos são imprevisíveis, especialmente em mundo onde as palavras de ordem são a busca pela experiência e pelo prazer. 
Desde a sua primeira edição, o Rock in Rio consagrou-se como um lugar de consumo, sem o qual o projeto não teria se materializado. Mas é no consumo do espetáculo, ele mesmo um produto, e nos demais atrelados a ele, que se encontra a lógica de sua criação, sobrevivência e sucesso. Todavia, antes de nos debruçarmos sobre a experiência Rock in Rio, convém reafirmar o que é o consumo, considerado por Canclini (2205), que recobra a concepção do duplo papel das mercadorias explicitado por Douglas e Isherwood (2004), como "o conjunto de processos socioculturais em que se realizam a apropriação e os usos dos produtos" (CANCLINI, 2005, p.60), enfatizando não apenas seu caráter de produtor de distinção, mas de integração e comunicação. Para o autor,

[...] um artesanato ou uma festa indígena, cujo sentido mítico é propriedade dos que pertencem à etnia que os gerou tornam-se elementos de distinção ou discriminação na medida em que outros setores da sociedade se interessam por eles e entendem em algum nível seu significado. Logo, devemos admitir que no consumo se constrói parte da racionalidade integrativa e comunicativa de uma sociedade (CANCLINI, 2005, p.63).

Configurado como um lugar para o consumo de sensorialidades, nas arenas do festival as pessoas querem mais do que comprar produtos, elas querem viver experiências, sonhar, envolver-se com as marcas de uma forma emocional, elas querem consumir experiências de forma prazerosa. Colin Campbell (2001, p. 115), a fim de compreender o comportamento hedonista do consumidor moderno, ressalta o papel do estímulo das sensações para a geração de prazer.

[...] o hedonista contemporâneo é um artista do sonho, que especiais habilidades psíquicas do homem moderno tornaram possível. Fundamental para este processo é a aptidão de obter prazer das emoções assim despertadas, pois, quando as imagens são ajustadas, também o são as emoções. Como uma consequência direta, criam-se fantasias convincentes, de tal modo que os indivíduos reagem subjetivamente a estas como se fossem reais. É esta uma propriedade nitidamente moderna, a aptidão de criar uma ilusão que se sabe falsa, mas se sente verdadeira. O indivíduo é tanto o autor como a plateia no seu próprio drama, "seu próprio" no sentido que ele o construiu, destaca-se nele, e constitui a soma total da plateia. Tudo isso altera drasticamente a natureza do hedonismo, pois não apenas o homem moderno colhe prazer em suas fantasias, mas, deleitando-se com elas, muda radicalmente sua concepção do lugar do prazer na vida real (CAMPBELL, 2001, p.115).

O autor ainda sobreleva que o espírito do consumismo moderno, "é tudo, menos materialista” (CAMPBELL, 2001). Para o autor, "sua motivação básica é o desejo de 
experimentar na realidade os dramas agradáveis de que já desfrutaram na imaginação, e cada 'novo' produto é visto como se oferecesse uma possibilidade de concretizar esta ambição". Assim, as experiências lúdicas que as marcas oferecem nas arenas do Rock in Rio se alinham com as proposições de Campbell, sobre o papel dos devaneios com produtores de desejo (CAMPBELL, 2001, p.131-132). Para o autor,

Que o desfrute imaginativo de produtos e serviços é uma parte crucial do consumismo contemporâneo se revela pelo importante lugar ocupado, na nossa cultura, mais pelas representações dos produtos do que pelos próprios produtos. Isso não só abrange abertamente os anúncios e catálogos comerciais, como as revistas, periódicos, cartazes, cartões, calendários e até obras de arte. Em muitas destas, a fronteira entre a representação dos interesses de determinado fabricante e distribuidor [...] e as imagens produzidas primeiramente para o entretenimento é claramente distinguível, sugerindo que as duas coisas preencham a mesma função de facilitar o hedonismo imaginativo. Em outras palavras, as pessoas "desfrutam" dessas imagens em grande parte da mesma forma que desfrutam de um romance ou filme (CAMPBELL, 2001, p.134).

Quando Campbell evidencia a aproximação do consumo com o entretenimento, tendo a comunicação como propulsora, nos aproximamos das reflexões de Featherstone (1995) e Pine e Gilmore (2000). O primeiro sobreleva a aproximação entre locais de consumo e elementos carnavalescos, como já dissemos anteriormente, enquanto o segundo identifica neste processo a ascensão da economia da experiência. Para esta reflexão, consideramos importante salientar o pensamento de Alvin Toffler (1998) desenvolvido ao longo da década de 1960 e explicitado na obra "O Choque do Futuro".

Publicada pela primeira vez em 1970, sobre essa ascensão das sensações, a obra de Toffler não só vaticina as concepções de Pine e Gilmore, tornadas públicas quase duas décadas depois (1998), mas também faz contato com outras obras publicadas posteriormente, como Simulacros e Simulações de Jean Baudrillard (1991), tratando da experiência humana como simulação da realidade, publicada pela primeira vez em 1981 e A economia do entretenimento de Michael J. Wolf (1999), relatando que este ponto está se tornando um dos principais tópicos do mundo dos negócios. Sobre o viés lúdico atrelado à experiência do consumo, Douglas Kellner (2004, p. 6) conclui que:

Num mundo de negócios competitivos, o "fator diversão" pode servir de ponte entre os negócios. Por essa razão, as corporações procuram se mostrar de forma mais divertida em seus anúncios, nos ambientes empresariais e comerciais e em seus websites. Os anúncios da Budweiser, por exemplo, mostram rãs falantes que nada nos falam sobre a cerveja, mas que chamam a 
atenção do público, enquanto a Pepsi usa personagens do filme Guerra nas Estrelas. Os atos de comprar, vender e jantar fora são codificados como uma "experiência", enquanto as empresas adotam um estilo do tipo parque temático. Lugares como o Hard Rock Café e a House of Blues não são famosos por seus cardápios; além disso, as pessoas freqüentam esses lugares por causa do ambiente, para comprar roupas e assistir a shows de artistas famosos. Apenas o fato de ter um website não é o suficiente. Ele deve ser um espetáculo interativo, que mostra não apenas produtos para serem vendidos, mas que oferece música e vídeos para serem baixados, jogos, prêmios, informações turísticas e "links para outros bons sites".

Portanto, o consumo da experiência Rock in Rio compõe-se da fruição de um amplo número de experiências oferecidas em suas plataformas on-line ou off-line pelo próprio evento e parceiros, antes e depois de acontecer, onde predomina, tal qual preconizado por Wolf (2003) ao tratar do fenômeno econômico, um mix de conteúdo de entretenimento e experiências. Para o autor,

Agora estamos claramente em um mundo de entretenimento. Um filme oferece uma viagem para outro tempo e espaço. Uma canção popular oferece três minutos de devaneio romântico (ou de comiseração para dorde-cotovelo). Entre em uma loja de roupas, e você entrará no mundo de acordo com Calvin ou Armani: as luzes, a música, a mobília e a decoração, os vendedores descolados criam a sensação de uma peça na qual você, o comprador, tem um papel principal (WOLF, 2003, p. 68).

O mercado de criação de experiências é um dos que se robustece em tempos destas novas relações com as marcas. Só para a edição do festival em 2013, a Dream Factory, empresa brasileira especializada em live marketing, foi responsável por "experiências inesquecíveis criadas, planejadas e executadas para 14 grandes marcas no Rock in Rio" (O GLOBO, p. 11, 18/09/2013), segundo anúncio publicado logo após o encerramento do festival. Nele, a empresa fez um convite para as marcas: "Se você precisa realizar projetos de Live Marketing que encantem, engajem e emocionem o seu público, entre em contato com a gente".

Além da Dream Factory, outras indústrias criativas colaboraram para a materialização da Disneylândia do rock, com suas experiências que pretendem "tocar as pessoas, o que deixa a atividade muito mais complexa do ponto de vista dos riscos envolvidos, como acidentes, entre outros fatores", conforme explicitou Roberta Medina durante o primeiro congresso brasileiro de live marketing (LORENTE, 2013, p.2). O balanço da edição do festival de 2013 apresenta alguns números e indica o prestígio popular destas atrações que atraíram e emocionaram quase cem mil pessoas. 
Roda-Gigante Itaú e Prefeitura do Rio de Janeiro: cerca de 37 mil pessoas Tirolesa Heineken: cerca de 5,9 mil pessoas Turbo Drop Trident: mais de 20 mil pessoas Montanha Russa Chilli Beans: mais de 28 mil pessoas Parede de escalada Correios: 3,6 mil pessoas Total: 95,7 mil pessoas usufruíram das atividades paralelas na Cidade do Rock (ROCK IN RIO, 2013).

Na edição anterior, em 2011, foram 17 marcas patrocinadoras: Itaú, Claro, Heineken, Trident e Volkswagen e os apoiadores Chilli Beans, Correios, Editora Globo, Ipiranga Petroquímica, Kraft Foods (Halls e Club Social, Lacta e Bis), Paco Rabanne, Philips, Prefeitura do Rio, Sky, TAM, Universidade Estácio e Wizard (MACEDO, 2011, p.2).

Ainda em 2013, apenas considerando os patrocínios fora da abrangência da Lei Rouanet, foram captados mais de R\$ 135 milhões distribuídos em 70 marcas (OLIVEIRA, 2015). De acordo com essa mesma matéria, "as ativações das companhias criam verdadeiras experiências - algo que se tornou foco do mercado de entretenimento", o que representou, em 2015, 643 produtos, divididos em 76 categorias, de 42 marcas. Em números, o festival Rock in Rio registra ao longo da sua história:

20 edições desde 1985

2.301 artistas escalados

10.2 milhões de pessoas na plateia

237.5 mil empregos gerados

12 milhões de fãs online

119 dias de magia desde 1985

76 milhões de pessoas alcançadas nas redes em 2019 (ROCK IN RIO, s.d)

Ao longo de mais de trinta anos, o festival Rock in Rio vem sendo um exemplo de evento cultural que impacta a economia da cidade do Rio de Janeiro e, de certa forma, projeta a imagem da cidade pelo menos nos quatro países que já receberam edição desse grande evento (Portugal, Espanha, Estados Unidos e, claro, Brasil).

\section{Um festival de criatividade}

Em 1947, Theodor Adorno (1987, p.287) criou o termo indústria cultural em livro publicado com Horkheimer, cujo tema era cultura de massa. As críticas severas à indústria que transformaria cultura em mercadoria foram mais tarde amenizadas pelo próprio Adorno, que reconheceria a existência ainda de "um espaço de liberdade" (ADORNO, 1968 apud 


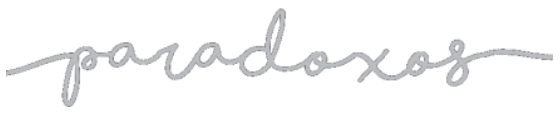

FADUL, 1994). Grande parte dos textos de Adorno ressalta, entretanto, o caráter nocivo da indústria cultural, pois, para o autor,

Ela vive, em certo sentido, como parasita sobre a técnica-artística da produção de bens materiais, sem se preocupar com a determinação que a objetividade dessas técnicas implica para a forma intra-artística, mas também sem respeitar a lei formal da autonomia estética. Daí resulta a mistura, tão essencial para a fisionomia da indústria cultural, de streamlining, de precisão e de nitidez fotográfica de um lado, e de resíduos individualistas, de atmosfera, de romantismo forjado e já racionalizado, de outro (ADORNO, 1987, p.290).

Mais tarde, Umberto Eco, na obra Apocalípticos e Integrados (1979), também condenaria as visões excessivamente pessimistas da comunicação de massa de Adorno e Horkheimer. Mesmo partilhando de muitas das ideias dos apocalípticos, ou seja, tendo uma visão negativa do presente, o autor recusa o conceito catastrofista que conduziria a uma atitude paralisante, sem abrir mão da crítica: "Para o integrado não existe o problema de essa cultura sair de baixo ou vir confeccionada de cima para consumidores indefesos" (ECO, 1979, p. 9).

Pratt (2007) e Hesmondhalgh (2008), por outro lado, destacam mais as contradições da indústria cultural que o seu caráter maléfico. Além disso, juntam a esta discussão o conceito da indústria criativa que, acreditamos, poderia dar novo fôlego para a velha indústria cultural, considerando, inclusive, a existência de pequenas indústrias culturais. Andrew Pratt (2007) aponta o elo entre as duas ao afirmar que "as chamadas indústrias criativas [...]: na maior parte dos casos, se referem às anteriormente conhecidas como indústrias culturais". O mesmo Pratt (2007) destaca, entretanto, que não é tão simples, porque só a centelha criativa não basta: é preciso o elo com os produtores e distribuidores. Embora ambas visem ao lucro, mesmo que se valendo de discursos diferentes para legitimar suas ações e contendo outros interesses, acreditamos que a novidade do termo ou do formato da indústria criativa atuam mais como uma pretensão para mostrar que é um modelo diferente da velha indústria cultural, distinção que se mostra muitas vezes mediante iniciativas microscópicas, em vez de realmente numa nova proposta.

$\mathrm{O}$ conceito chave de economia criativa seria o que foi apresentado no Creative Industries Mapping Document, elaborado em 1998 pelo Department of Culture, Media and Sports do Reino Unido. Segundo o documento, as indústrias criativas seriam "aquelas que têm origem na criatividade, capacidade e talento individuais, e que potencializam a criação 
de riqueza e de empregos através da produção e exploração da propriedade intelectual" (DCMS, 1998). O documento, reapresentado em 2001, enumera as seguintes áreas do ramo: publicidade, arquitetura, artes visuais e antiguidades, artesanato e joalharia, design, design de moda, cinema, vídeo e audiovisual, software educacional e de entretenimento, música, artes performativas, edição, software e serviços de informática, televisão e rádio.

Hesmondhalgh (2008) não confirma, mas dá pistas de que a ideia de indústrias criativas foi percebida no uso contínuo de artes e cultura para a regeneração urbana de cidades na década de 1990, cujo desdobramento resultaria no surgimento dos clusters criativos. Segundo o autor,

Estes incluem a promoção da diversidade cultural e da democracia, lugarcomercialização nos interesses do turismo e do emprego, estimulando uma abordagem mais empresarial para as artes e a cultura, uma forma de estimular a inovação e a criatividade, e encontrar um novo uso para antigos edifícios e locais abandonados. Mommaas observa que, embora algumas estratégias de agrupamento estejam limitadas a atividades artísticoculturais, a maioria deles incorpora muitos outros elementos de lazer e entretenimento - complexos de fitness bares, saúde e assim por diante (HESMONGHALGH, 2008, p. 558, tradução nossa).

Sobre as especificidades das empresas que se reúnem nos clusters das chamadas indústrias criativas, um texto da Comissão de Tecnologia da Informação e Criatividade da Academia Nacional de Ciências dos Estados Unidos ressalta três componentes que as caracterizariam, sem deixar de destacar a importância do papel das práticas culturais populares:

Um componente das indústrias criativas consiste de atividade econômica diretamente relacionada ao mundo das artes em particular, as artes visuais, artes do espetáculo, a literatura e editoras, fotografia, artesanato, bibliotecas, museus, galerias, arquivos, património e festivais de artes. Um segundo componente é constituída atividade relacionada a eletrônica e outras mais recentes meios de comunicação nomeadamente broadcast, cinema e televisão, música gravada, e software e digital mídia. E um terceiro componente consiste em atividades relacionadas com o projeto, tais como arquitetura, interiores e paisagismo, design de produto, gráficos e design de comunicação e moda (MITCHELL, 2003, p. 19, tradução nossa).

Enquanto alguns pesquisadores ligam este ramo da economia às novas tecnologias e à existência de consumidores participativos, para outros a marca da economia criativa seria o talento individual. Um terceiro grupo acredita que o diferencial seria ter como resultado a propriedade intelectual. A entrevista da consultora Anna Jaguaribe (2006) ao Portal Literal 


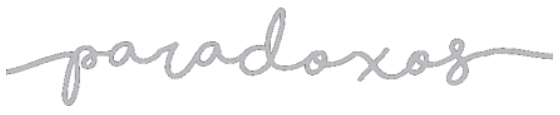

traz uma das definições que consideramos mais abrangentes sobre este ramo da economia da criatividade no caso do Brasil.

Elas produzem bens e serviços que utilizam imagens, textos e símbolos como meio. São indústrias guiadas por um regime de propriedade intelectual e que, na verdade, empurram a fronteira tecnológica das novas tecnologias da informação. Em geral, existe uma espécie de acordo que as indústrias criativas têm um coregroup, um coração, que seria composto de música, audiovisual, multimídia, software, broadcasting e todos os processos de editoria em geral (JAGUARIBE, 2006).

O mesmo autor destaca a dificuldade em afirmar o que faz ou não parte das indústrias criativas:

A coisa curiosa é que a fronteira das indústrias criativas não é nítida. As pessoas utilizam o termo como sinônimo de indústrias de conteúdo, mas o que se vê cada vez mais é que na grande gama de processos, produtos e serviços que são baseados na criatividade, mas que têm as suas origens em coisas muito mais tradicionais, como o craft, folclore ou artesanato estão cada vez mais utilizando tecnologias de management, de informática para se transformarem em bens, produtos e serviços de grande distribuição (JAGUARIBE, 2006).

A partir destes conceitos, verificamos que o Rock in Rio se enquadra como um produto da indústria criativa (e da indústria cultural), uma vez que atende a quase todos os requisitos enumerados por Jaguaribe (2006), além de já ser considerado patrimônio, como foi explicitado pela secretária de Economia Criativa do Ministério da Cultura, Cláudia Leitão (2013), em entrevista ao Correio Braziliense: "Temos todas as artes: música, dança, circo, o audiovisual, os softwares, os games, o patrimônio cultural e natural, por exemplo, a Serra da Capivara e o Rock in Rio".

É nossa crença que a ideia de comunicação de massa, um dos princípios da indústria cultural e que não é requisito fundamental dos produtos da indústria criativa, ainda que não seja excludente, aproxima este megaevento contemporâneo mais do conceito de indústria cultural do que de indústria criativa. Acreditamos, inclusive, que há a possibilidade de que uma contenha a outra, criando produtos de tamanhos e impactos variados. Neste caso, embora o Rock in Rio seja uma realização da indústria criativa, traz consigo também o selo da indústria cultural, já que, desde o início concebido como um megaevento, sem o envolvimento de um público massivo sua realização não seria viável, tanto para financiar a sua megaestrutura quando para gerar o impacto midiático na sociedade - ambos, causa e efeito destes espetáculos. 


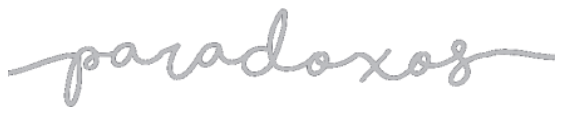

Com uma política recente de monitoração e estímulo para a indústria criativa (ao contrário do que acontece na Inglaterra, por exemplo, que pretende se tornar um World Creative Hub, ou seja, um Centro Criativo para o Mundo, apresentando estratégias claras), apenas em fevereiro de 2012 foi criado no Brasil o Observatório Brasileiro da Economia Criativa (OBEC) e, em junho de 2012, a Secretaria de Economia Criativa, ambos ligados ao Ministério da Cultura, bem como foi elaborado o Plano Nacional da Economia Criativa, ainda que já existissem pesquisadores atentos a essas iniciativas.

A Federação das Indústrias do Estado do Rio de Janeiro (FIRJAN) realizou em 2008 o estudo pioneiro "Cadeira da Indústria Criativa no Brasil” e, em 2012, publicou o Mapeamento das Indústrias Criativas do país. O estudo revelou que, em 2011, 243 mil empresas formavam o núcleo brasileiro de indústria criativa, responsável por 2,7\% de tudo que era produzido no Brasil, o equivalente a $\mathrm{R} \$ 110$ bilhões. Além disso, o mercado formal da indústria criativa empregava 810 mil profissionais - ou $1,7 \%$ dos trabalhadores brasileiros (INDÚSTRIA CRIATIVA, 2012, p.11).

Embora o estudo da Firjan saliente que os setores de arquitetura e engenharia, seguidos pelo de moda, que chega a empregar 1.2 milhão de pessoas, sejam os mais vigorosos da indústria criativa brasileira, espetáculos como o Rock in Rio, envolvendo profissionais de todos os segmentos criativos, como música, artes cênicas e publicidade, ainda que mantenham equipes permanentes de profissionais, absorvem temporariamente milhares de profissionais. Além disso, a edição 2013 do festival gerou, segundo a Riotur (2013), um impacto de mais de $\mathrm{R} \$ 1$ bilhão na economia da cidade do Rio de Janeiro, movimentando a economia meses antes e depois de acontecer. Os organizadores informam também que, diariamente, aproximadamente 15 mil pessoas trabalham no evento (MEDINA, 2013). Esses números fazem com que outros lugares também queiram o seu bilhão, ainda que para isso tenham que se colar à marca e ao modelo brasileiro.

\section{Considerações Finais}

Convertido em um case de sucesso da indústria criativa nacional, modelo e marca já foram exportados para quatro países, como os Estados Unidos. De acordo com Roberto Medina (2014), enquanto o maior evento americano do gênero tem um investimento publicitário de 5,5 milhões de dólares, no Rock in Rio o investimento é de 52 milhões de dólares: "As marcas do Rock in Rio em todos os países se repetem sempre, são as mesmas 


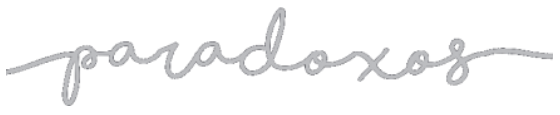

marcas, ou seja, não é o cara que está pagando que se emocionou com o projeto, é exatamente um negócio que tem um retorno fantástico para as marcas, e tem mesmo" (MEDINA, 2014). O empresário destaca também que, embora os Estados Unidos sejam líderes no ramo do entretenimento, neste tipo de evento de música, estranhamente, não é. Além disso, o Rock in Rio USA, segundo Medina (2014), se beneficiou de uma estrutura que atende à indústria criativa do entretenimento norte-americana e da pouca interferência do poder público, o que no Brasil seria um complicador, embora o projeto não tenha se repetido.

Com resultados expressivos e positivos em quase todos os seus desdobramentos, o Rock in Rio é energizado também pelas possibilidades das plataformas na internet, convertidas em um negócio e onde pulula a marca transmidiática. Ou seja, não se usa o padrão de "contar uma determinada história" em um único meio. A experiência é ampliada, cada mídia - site, Instagram, TikTok, possuindo um conteúdo original adequado a suas características e a seu público, o que amplia a visibilidade do festival, gera conteúdo frequente para esse produto da indústria criativa e desperta o interesse do público espectador.

\section{Referências}

ADORNO, Theodor Wiesengrund. "A indústria cultural”. In: COHN, Gabriel. (Org.). Comunicação e indústria cultural. 5a ed. São Paulo: T.A. Queiroz, 1987. p. 287-295.

ARANTES, Otília. Berlim e Barcelona: duas imagens estratégicas. São Paulo: Annablume, 2012.

AZEVEDO, André Nunes de. "A Capitalidade do Rio de Janeiro: Um exercício de reflexão histórica". In: AZEVEDO, André Nunes de (Org.). Rio de Janeiro: Capital e Capitalidade. Rio de Janeiro: Departamento Cultural/NAPE/DEPEXT/SR-3-UERJ, 2002.

BAUDRILLARD, Jean. Simulacros e simulações. Lisboa: Relógio D'Água, 1991.

BAUMAN, Zygmunt. Comunidade: a busca por segurança no mundo atual. Rio de Janeiro: Jorge Zahar Editor, 2003.

BAUMAN, Zygmunt. Identidade: entrevista a Benedetto Vecchi. Rio de Janeiro: Jorge Zahar Editor, 2005.

BELLOTTO, Tony. “A poesia concreta do Rock in Rio”. Folha de São Paulo, São Paulo, 23 set. 2011. Opinião, p. A3.

BLANCO, Gisela. "Verbete Draft: o que é Economia Criativa". Draft, 18 mar. 2015. Disponível em: https://projetodraft.com/verbete-draft-o-que-e-economia-criativa/. Acesso em: 11 set. 2021. 


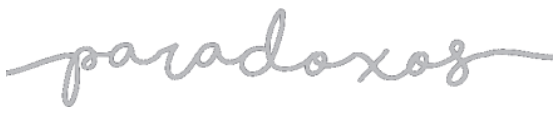

CAMPBELL, Colin. A ética romântica e o espírito do consumismo moderno. Rio de Janeiro: Rocco, 2001.

CAMPOS, Augusto; PIGNATARI, Décio; CAMPOS, Haroldo. Teoria da poesia concreta: textos críticos e manifestos 1950 - 1960. São Paulo: Duas Cidades, 1975.

CANCLINI, Néstor Garcia. Consumidores e Cidadãos. 5. ed. Rio de Janeiro: Editora UFRJ, 2005.

CASTRO, Mariana. Empreendedorismo Criativo. São Paulo: Portfolio Penguin, 2014.

DEPARTMENT FOR CULTURE, MEDIA AND SPORTS (DCMS). Creative Industries Mapping Document. London: DCMS, 1998.

DOUGLAS, Mary; ISHERWOOD, Baron. $O$ mundo dos bens: para uma antropologia do consumo. Rio de Janeiro: Ed. UFRJ, 2004.

ECO, Umberto. Apocalípticos e Integrados. São Paulo: Perspectiva, 1979.

ERNST \& YOUNG. Tempos de Cultura: O primeiro mapa global das indústrias culturais e criativas. Dez. 2015. Disponível em: https://www.spautores.pt/assets_live/12843/eyculturaltimes-2015-pt.pdf. Acesso em: 09/11/2019.

FADUL, Ana Maria. "Indústria cultural e comunicação de massa". 2004. Disponível em: http://www.crmariocovas.sp.gov.br/pdf/c_ideias_17_053_a_059.pdf. Acesso em: 10 set. 2021.

FEATHERSTONE, Mike. Cultura de consumo e pós-modernismo. São Paulo: Studio Nobel, 1995.

FOLHA. "Folha e Itaú Cultural realizam $2^{\mathrm{a}}$ edição de webinário sobre cultura na pandemia". Disponível em: https://www1.folha.uol.com.br/seminariosfolha/2021/08/folha-e-itau-culturalrealizam-2a-edicao-de-webinario-sobre-cultura-na-pandemia.shtml. Acesso em: 11 set. 2021.

HESMONDHALGH, David. "Cultural and Creative Industries". In: BENNETT, Tony; FROW, John. (Orgs.). The Sage Handbook of Cultural Analysis. London \& Los Angeles: Sage, 2008.

INDÚSTRIA CRIATIVA. Mapeamento da indústria criativa no Brasil. Rio de Janeiro: Sistema Firjan, 2012.

JAGUARIBE, A. Indústrias criativas. 2006. Disponível em:

http://www.literal.com.br/acervodoportal/industrias-criativas-1388/. Acesso em: 19 jul. 2013.

KELLNER, Douglas. “A Cultura da mídia e o triunfo do espetáculo”. Revista Líbero, São Paulo, ano VI, v. 6, n. 11, p. 4-15, 2004.

LINS, Flávio; BRANDÃO, Cristina. Cariocas do brejo entrando no ar: o rádio e a televisão na construção da identidade juiz-forana (1940-1960). Juiz de Fora: Editora da UFJF, 2012. 
LORENTE, Beatriz Almodova. "Os primeiros passos do Live Marketing". 2013. Disponível em: http://www.meioemensagem.com.br/mob/comunicacao/interna.html?path=/home/comunicacao/no ticias/2013/07/29/Os-primeiros-passos-do-Live-Marketing. Acesso em: 11 set. 2021.

MACEDO, Rosayne. "Megaespetáculo de interação entre marcas e consumidores". 2011. Disponível em: http://www.meioemensagem.com.br/home/marketing/noticias /2011/09/22/Megaespetaculo-de-interacao-entre-marcas-e-consumidores.html. Acesso em: 11 set. 2021.

MAPEAMENTO da Indústria Criativa no Brasil. FIRJAN SENAI. 2019. Disponível em: https://www.firjan.com.br/EconomiaCriativa/downloads/MapeamentoIndustriaCriativa.pdf. Acesso em: 11 set. 2021.

MEDINA, Roberto. "Roberto Medina: entrevista à TV Estadão". 2014. Disponível em: http://tv.estadao.com.br/videos,roberto-medina-mercado-americano-e-mais-profissio nalque-o-brasileiro,227752,253,0.htm. Acesso em: 10 set. 2021.

MEDINA, Roberta. Os megaprodutores. Rio de Janeiro, Casa do Saber, 16 ago. 2013, palestra.

MITCHELL, William J.; INOYSE, Alan S.; BLUMENTHAL, Marjory S. Beyond Productivity: information, technology, innovation, and creativity. Washington: National Academy Press, 2003.

NEVES, Marília. "A crise do entretenimento na pandemia: 350 mil eventos adiados ou cancelados e R $\$ 90$ bilhões 'perdidos'”. Disponível em: https://g1.globo.com/poparte/noticia/2021/02/17/a-crise-do-entretenimento-na-pandemia-350-mil-eventos-adiadosou-cancelados-e-r-90-milhoes-perdidos.ghtml. Acesso em: 11 set. 2021.

OLIVEIRA, Priscila. "Rock in Rio: um festival para espectadores e empresas". Disponível em: https://www.mundodomarketing.com.br/entrevistas/34585/rock-in-rio-um-festivalpara-espectadores-e-empresas.html. Acesso 14 set. 2021.

PAIVA, Raquel; SODRÉ, Muniz. Cidade dos artistas: cartografia da televisão e da fama no Rio de Janeiro. Rio de Janeiro: Mauad, 2004.

PINE, Joseph; GILMORE, James. L'economia delle esperienze. Milão: Etas, 2000.

PORTER, Michael E. A vantagem competitiva das nações. $16^{\mathrm{a}} \mathrm{ed}$. Tradução Waltensir Dutra, Editora Elsevier, 1989.

PRATT, Andrew. "An economic geography of the cultural industries”. In: LEYSHON, Andrew; McDOWELL, Linda; LEE, Roger. (Orgs.). The sage handbook of economic geography. London: SAGE, 2007. p. 323-337.

RELATÓRIO sobre os impactos econômicos da covid-19 economia criativa. Fundação Getúlio Vargas (FGV). Junho 2020. Disponível em:

https://fgvprojetos.fgv.br/artigos/impactos-economicos-da-covid-19-economia-criativajulho-2020. Acesso em: 14 set. 2021. 
RIDING, Alan. "From Rod Stewart to heavy metal at rock". 1985. Disponível em: http://www.nytimes.com/1985/01/21/arts/fromrodstewarttoheavymetalatrockfestivalnearrio dejaneiro.html. Acesso em: 11 set. 2021.

ROCK IN RIO. "História”. Disponível em: https://rockinrio.com/rio/pt-br/historia/. Acesso em: 14 set. 2021.

SÁNCHEZ, Fernanda. A reinvenção das cidades para um mercado mundial. $2^{\mathrm{a}} \mathrm{ed}$.

Chapecó, SC: Argos, 2010.

SÃO PAULO. "Câmara recebe conferência sobre Economia Criativa em São Paulo". 20 ago. 2015. Disponível em: http://www.camara.sp.gov.br/blog/camara-recebe-conferenciasobre-economia-criativa-em-sao-paulo/. Acesso em: 11 set. 2021.

\section{SECRETARIA DE ESTADO DE CULTURA E ECONOMIA CRIATIVA DO RIO DE} JANEIRO. Cultura e Economia Criativa. Disponível em: http://cultura.rj.gov.br/economiacriativa/. Acesso em: 14 set. 2021.

THE GUARDIAN. "The world cities with the most powerful brands get the data". Disponível em: http://www.theguardian.com/cities/datablog/2014/may/06/world-citiesmost-powerful-brands-get-the-data. Acesso em: 12 set. 2021.

THORPE, Vanessa. "Why UK risks losing out in the global 'arts race"”. The Guardian, 9 jan. 2016. Disponível em: https://www.theguardian.com/culture/2016/jan/09/uk-globalarts-race-music-tv?CMP=share_btn_fb. Acesso em: 11 set. 2021.

TOFFLER, Alvin. O choque do futuro. 6. ed. Rio de Janeiro: Record, 1998.

WOLF, Michael J. The entertainment economy. How mega-media forces are transforming our lives. New York: Crown Publishing, 2003. 